\section{CURRENT ADVANCES IN} HIGH AVERAGE POWER DIODE-PUMPED LASERS

\begin{abstract}
MARTIN HANUS, MARTIN DIVOKY, PETR NAVRATIL, MICHAL CHYLA, JAN PILAR, ONDREJ DENK, ANTONIO LUCIANETTI
\end{abstract}

HiLASE Centre, IoP, Dolni Brezany, Czech Republic

DOI : 10.17973/MMSJ.2019_12_2019112

martin.hanus@hilase.cz

In the last two decades, the price of the laser diodes significantly dropped and made them an energy-effective solution for pumping high energy class high average power solid-state lasers. This is a significant advantage for the potential use of such lasers in industry, where operation cost is considered. The efficiency of such diode-pumped lasers is much higher compared to the previous generation of flashlamp-pumped solid-state lasers. In addition, the small size of the laser diodes allows a drastic reduction of the overall size of the solid-state lasers. This article will give a brief summary of the worldwide progress in the area of high energy high average power diode-pumped laser systems.

KEYWORDS

High, power, diode, laser

\section{INTRODUCTION}

The laser is now an essential tool in many different fields. From science to everyday life, there are countless things impossible to do without lasers. In industry, for a long time, lasers are used for cutting and welding, marking or measuring. With the development of lasers with higher energies and high repetition rates, the idea to enhance materials by laser shock peening or surface nanostructuring to improve performance and reliability of the material in the industrial scale and with low cost becomes reality. In the year 2009 a step toward efficient and compact laser weapons was made. With efficiency up to $20 \%$, diode pumped solid-state laser (DPSSL) at greater than $100 \mathrm{~kW}$ average output power was commissioned [Injeyan 2011].

The key is in the diode pumped solid-state laser and the milestone is a laser diode as a source. By itself, laser diode is a highly efficient device with up to $70 \%$ electrical to optical power conversion efficiency [Injeyan 2011].

For comparison, also in 2009, the the world's largest laser, the National Ignition Facility (see Figure 2) was comissioned. It is a flashlamp pumped laser with output energy above 1 Megajoule. However, electrical to optical power conversion efficiency in such system is much less than $1 \%$ (see Figure 1) [Scheps 2002]. Thus a lot of heat is produced that must be taken away and high voltage flashlamp accessories are maintenance and space demanding (see Figure 3)

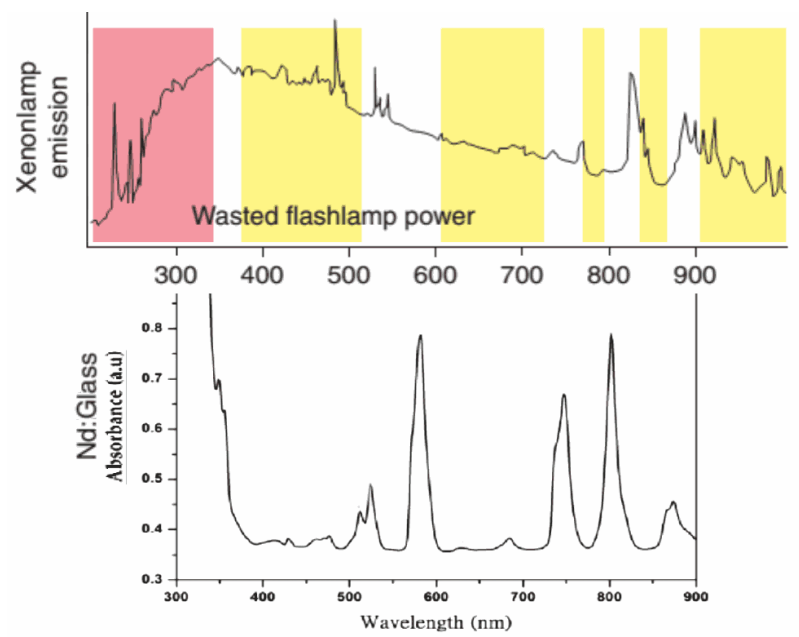

Figure 1. Xenon Flashlamp emission spectra [Injeyan 2011] in comparison with Nd ion absorbance in a phosphate glass [Tian 2015] as a demonstration of pumping inefficiency

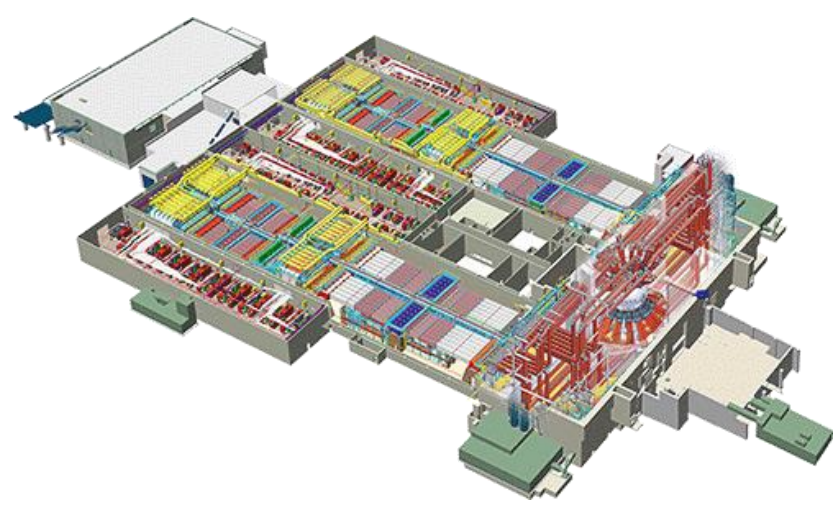

Figure 2. Basic layout of National Ignition Facility (NIF). [Wikipedia 2009]

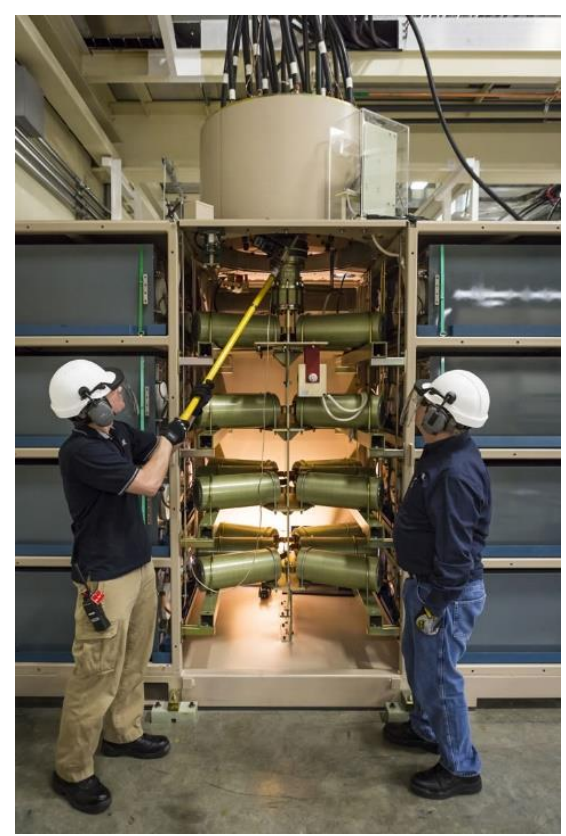

Figure 3. Power Conditioning System operators during an inspection of a capacitor bank in the NIF Capacitor Bay. (Each of its 192 modules stores $2 \mathrm{MJ}$ of energy and release it to the flashlamps in a $400 \mathrm{~ms}$ burst [Livermore1 2019]) 


\section{LASER DIODES}

From early days, laser diodes were mainly used as an optical pump for solid-state lasers. It was mainly due to lack of power and poor beam quality of laser diodes. Along with increase in their power, optics evolved too. Nowadays, there are available direct laser diode sources with enough power and sufficient beam quality (see Figure 6) to be used directly for applications. As the production of laser diodes rises, the prices are substantially dropping (see Figure 4Chyba! Nenalezen zdroj odkazů.), which makes them even more desirable. Unfortunately, laser diodes with unique properties like unusual wavelengths or narrow spectra are not so widespread and cost a lot more. For pumping of solid-state laser, however, the most important parameters are price per Watt of peak power, as more intensive pumping increases efficiency of the solid-state laser, and brightness of laser diodes that allows for more compact pump sources and DPSSL.

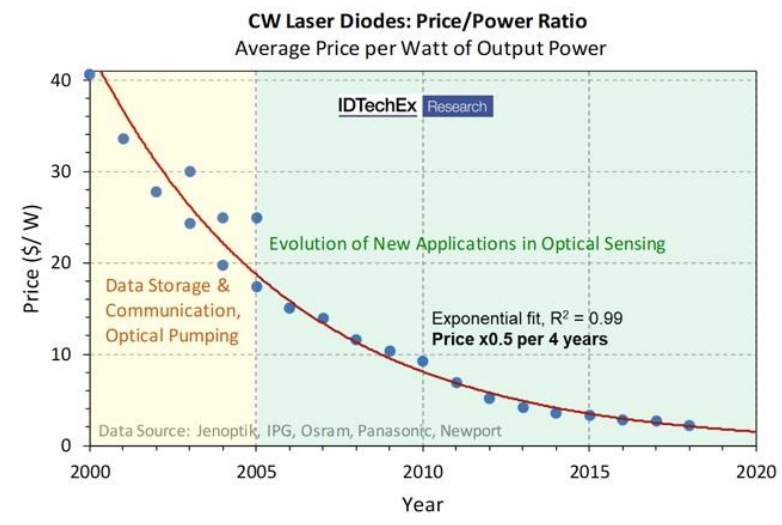

Figure 4. The decrease in laser diode price in last two decades [Abineri 2019]

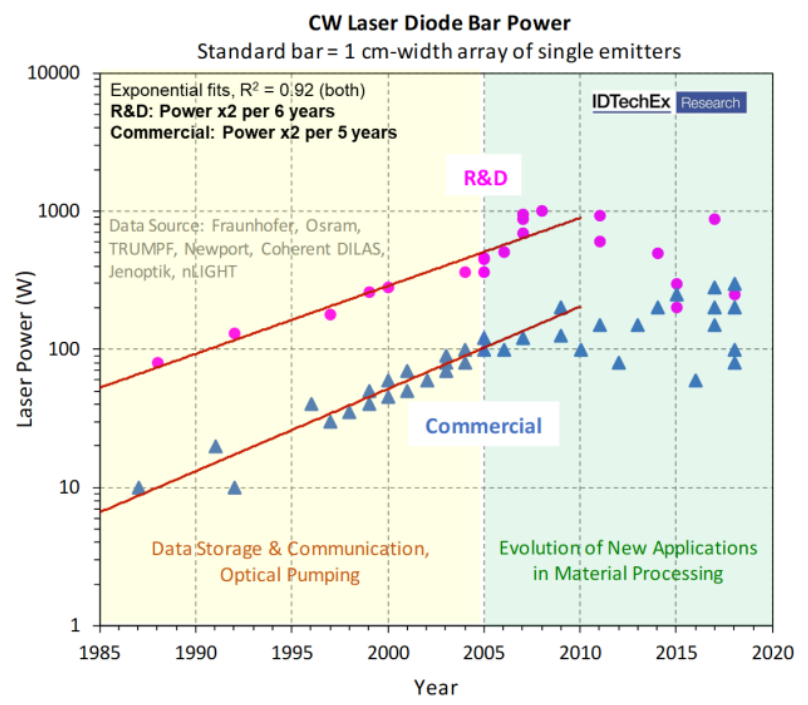

Figure 5. The increase in laser diode power [Abineri 2019]

\subsection{Evolution}

The beginning for semiconductor lasers can be dated to year 1963, when two independent proposals for double heterostructure laser design was given by Alferov and Kazarinov and by Kroemer [Alferov 2000]. Two crucial crystal growth techniques were developed in 1970s, molecular beam epitaxy (MBE) and metal organic chemical vapor deposition (MOCVD) [Welch 2000]. Further improvements in crystal growth technologies and refinement in laser design resulted in steady growth in both reliability and optical output power (see Figure 5 Chyba! Nenalezen zdroj odkazů.).

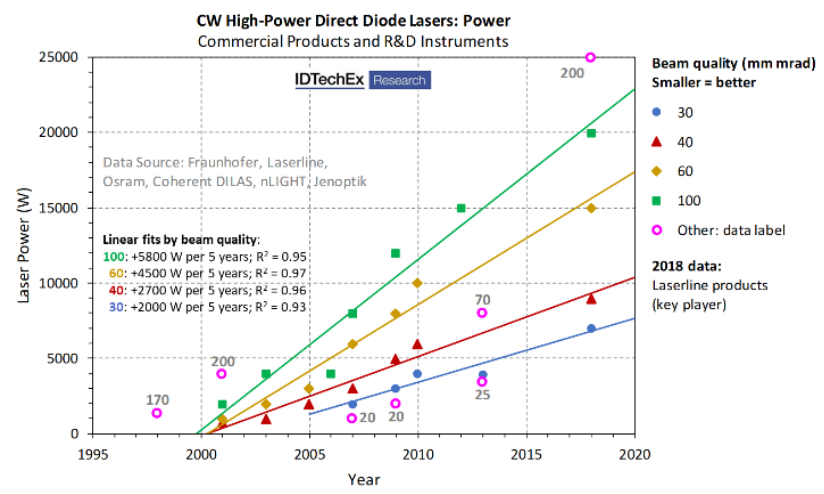

Figure 6. The increase in laser diode power of specific beam quality [Abineri 2019]

\subsection{Power scaling}

There are two methods, how to achieve high power output from laser diodes. First one is integrating many laser diodes, more precisely $p-n$ junctions, into a bar (see Figure 8). These are building blocks of a laser diode stack (see Figure 9), which is then integrated into a module (see Figure 7 and Figure 10) [Hamamatsu 2018], [II VI 2019], [Dilas 2019], [Livermore2 2019]. Second one is coupling each laser diode or bar into an optical fiber and then combining energy from many fibers into one (see Figure 11) [IPG 2019].

Both methods have ups and downs. The diode stacking main problem is reliability as failing of only one diode bar causes the whole stack to fail. Also cooling of the stack is not an easy task because of high power density. The fiber coupling method is mostly limited by the endurance of the output fiber, especially the face of the fiber.

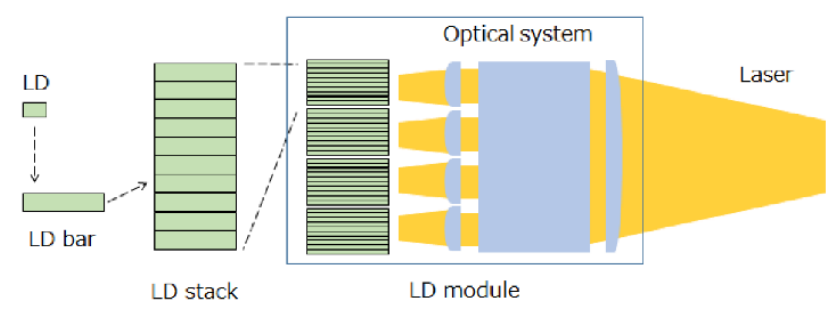

Figure 7. Laser diode (LD) integration into high power modules [Hamamatsu 2018]

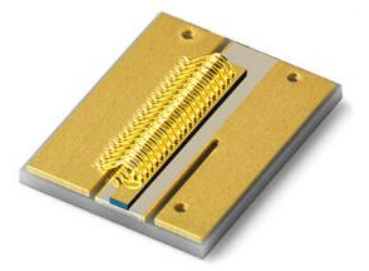

Figure 8. II-VI Laser Enterprises diode bar, edge emitting laser [II-VI 2019] 


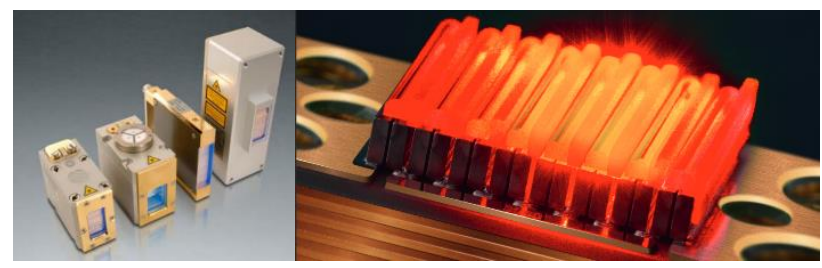

Figure 9. COHERENT/DILAS vertical stack design and packing shown on the left side, stack in operation shown on the right side [Dilas 2019]

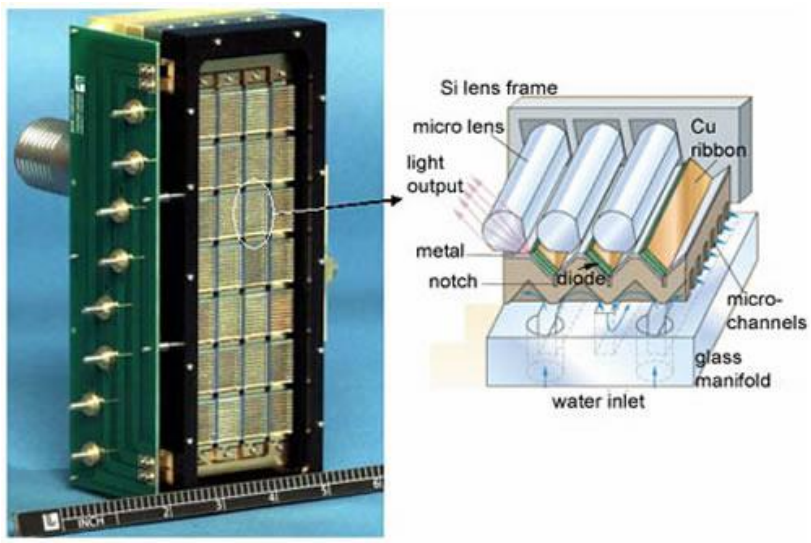

Figure 10. A Lawrence Livermore National Laboratory's (LLNLS) 41-kW array made up of 28 SiMM packages. The sketch illustrates a portion of a SiMM laser-diode package, actually available arrays are up to $100 \mathrm{~kW}$ [Livermore2 2019]

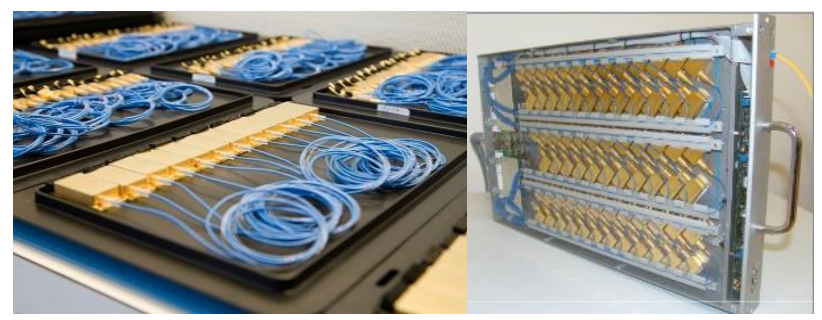

Figure 11. IPGs single emitter pumping solution basic building blocks on the left side and its integration into high power modules on the right side ([IPG 2019] and [Stark 2011])

\section{DIODE PUMPED LASER SYSTEMS}

Most common host material for diode pumped laser systems is yttrium aluminum garnet (YAG) which possesses good mix of high thermal conductivity, mechanical strength, and excellent optical quality [Kaminskii 1990]. In 1984, the first transparent ceramics of Nd:YAG was prepared [With 1984]. Nowadays, transparent ceramics is often used as gain media instead of singlecrystals, as it offers greater freedom in shape and material composition. Most commonly used active ions are Neodymium (Nd) and Ytterbium ( $\mathrm{Yb}$ ). Advantage of $\mathrm{Nd}$ is higher gain and lower lasing threshold (at room temperature), $\mathrm{Yb}$ allows higher doping concentrations and is more efficient especially at cryogenic temperatures [Injeyan 2011].

In practical use, there are many parameters to fine tune ([Weck 2008], [Sugioka 2014]), so the laser does what is desired. Some applications are sensitive to beam quality (micromachining), while others require only beam uniformity [laser shock peening]. Important are also wavelength (reflects processed material properties like absorption and reflection) or pulse width (reflects desired effect like drilling, welding or transforming). In industry, most important measure is productivity, where output energy and average power come into picture. Currently the average power is limiting usage of pulsed laser in industry, so a brief introduction to the world of high average power diode-pumped laser systems will be given.

For specific research activities, there are over 50 petawatt class lasers currently operational [Danson 2015]. It is a mix of flashlamp and diode pumped lasers. They are used for exotic physics that include particle acceleration, inertial confinement fusion, radiation therapy, and as a source for generation of $x$-rays, electrons, protons, neutrons and ions.

For practical use in manufacturing, there is no emphasis on extreme peak power. Simplicity and reliability is what drives these designs. The power density in such compact laser systems is extreme and the limiting factor for maximal output in minimal size is the heat dissipation from gain media and damage threshold of optics. Beam quality degrades as the heat generated in the gain media increases. Limiting the laser operation time, improving the cooling system or adding adaptive optics can partially compensate thermal degradation of the beam quality that can be near diffraction limit even for high average power operation, for example below 1.5 times diffraction limit for multi-slab system [Mason 2017] or $\mathrm{M}^{2}<2$ for thin disk system [Chyla 2018]. Several techniques were developed to overcome excessive heat generation. Probably the easiest solution is to briefly run the laser and then let it cool down on its own [Livermore3 2019]. This concept is called heat capacity laser (HCL) [Injeyan 2011]. In the Figure 12, there is simplified drawing of LLNLs version (for a real one in operation see Figure 14) using Nd:YAG slabs with cobalt doped gadolinium gallium garnet (GGG) cladding (see Figure 13) to suppress amplified spontaneous emission (ASE) that would otherwise significantly decrease the laser's output power. In 2006, such laser achieved power of 67 kilowatts in 5 seconds burst [Livermore3 2019].

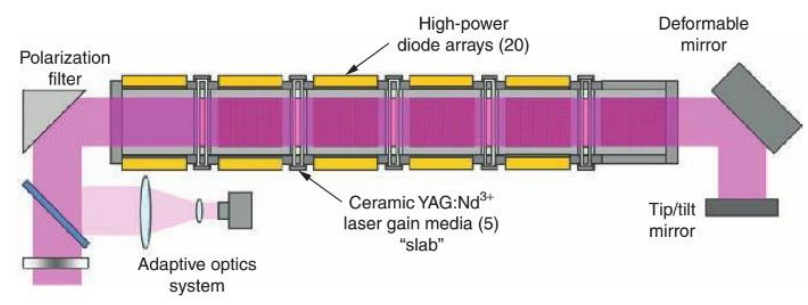

Figure 12. Heat-capacity laser architecture in use at LLNL [Injeyan 2011]

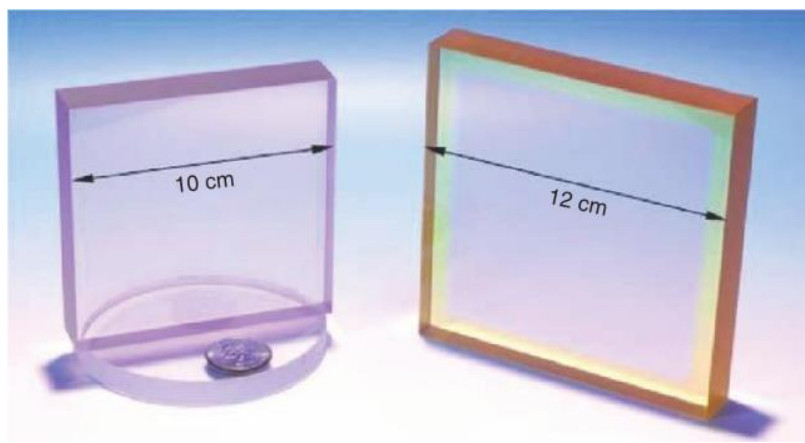

Figure 13. Transparent ceramic laser gain media of Nd:YAG on the left side and Nd:YAG with cobalt doped gadolinium gallium garnet (GGG) cladding to suppress amplified spontaneous emission (ASE) manufactured by Konoshima Chemical Company, Ltd. and Baikowski Japan Company [Injeyan 2011] 


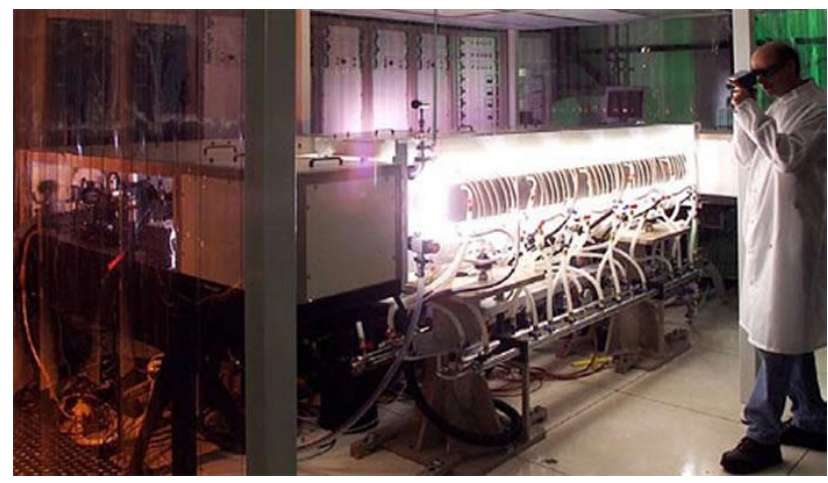

Figure 14. Heat-capacity laser in operation at LLNL [Livermore3 2019]

Concept of zigzag slab lasers allows efficient pumping and cooling of the laser gain media from sides (see Figure 15). The laser light travels inside the slab with the help of, total internal reflections from sides. A DP25 laser for precision machining with average power $5.4 \mathrm{~kW}$ was developed in 2002 [Machan 2002].

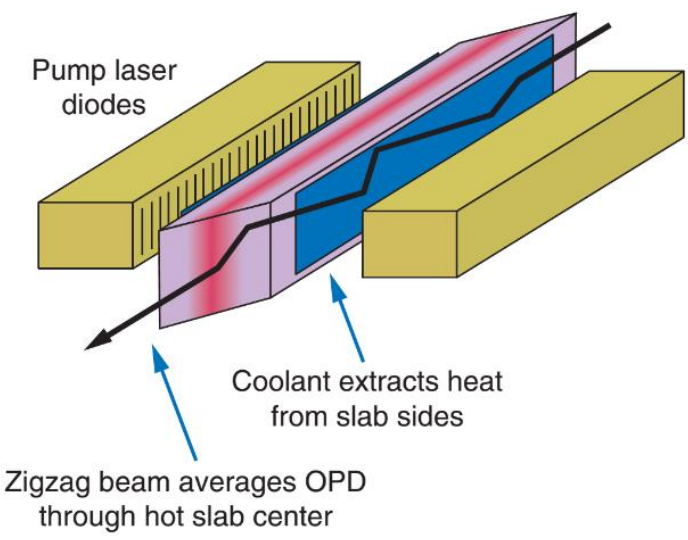

Figure 15. Design of a side-pumped zigzag slab laser (OPD: optical path difference) [Injeyan 2011]

Another concept is based on very thin gain media and thus called thin disk laser (developed in 1992 [Giesen 1994]). One face of the disc is cooled and acts as a mirror, the other is used to input and extract energy (see Figure 16). Many passes of both pump and laser light are needed to efficiently store and then extract the energy. Commercially available thin disk lasers with output power $12 \mathrm{~kW}$ [Trumpf 2019].

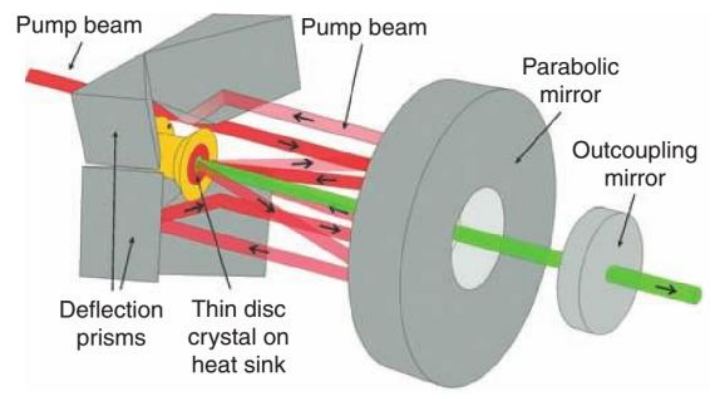

Figure 16. Design of a thin disc laser [Injeyan 2011]
Master Oscillator Power Amplifiers (MOPA) concept allows formation of a low power beam with tailored spatial and temporal characteristics using a master oscillator (MO) that is further amplified in one or more stages of power amplifiers (PA). Faraday isolators are typically required to prevent feedback between the $\mathrm{MO}$ and successive PAs. The extracted power is limited by thermal lensing and depolarization [Khazanov 1999]. Two typical MOPA systems were recently commissioned in Czech Republic. Bivoj laser placed at HiLASE has been built by STFC Rutherford Appleton Laboratory in cooperation with HiLASE (see Figure 17) and HAPLS at ELI Beamlines built by LLNL in cooperation with ELI Beamlines (see Figure 19). Both are capable of delivering more than $1 \mathrm{KW}$ of average power, but with different peak powers. Bivoj has cryogenically cooled main amplifiers with transparent ceramic slabs of Yb:YAG with Cr:YAG cladding (see Figure 18) demonstrated $1 \mathrm{~kW}$ output power in 2016 [Mason 2017]. A new generation of $1 \mathrm{~kW}$ average power laser system based on cryogenically cooled multi-slab technology is already being developed together by HiLASE and STFC. Other groups are also eager to join in on production of similar systems, for example in Hamamatsu Photonics [Hamamatsu 2018], [Kurata 2019].

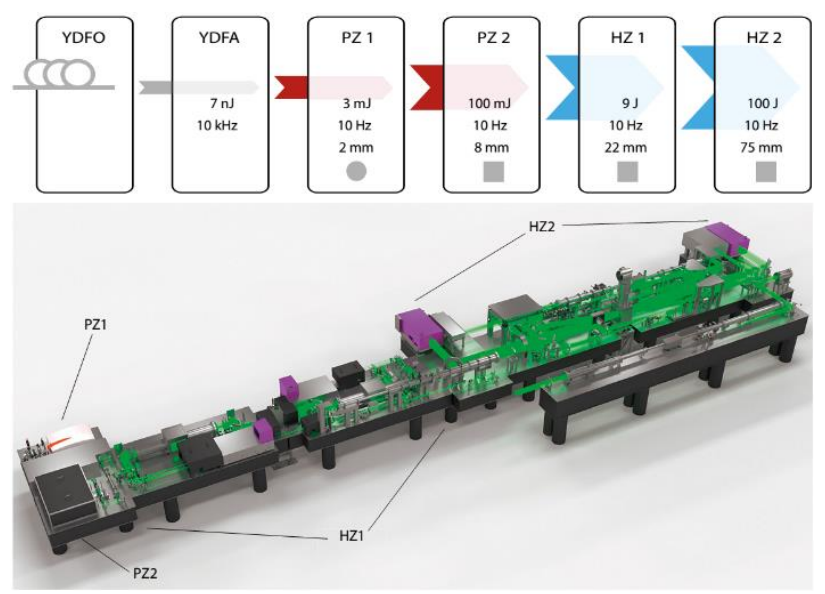

Figure 17. Design of Laser system Bivoj located at HiLASE facility, Czech Republic [David 2019]

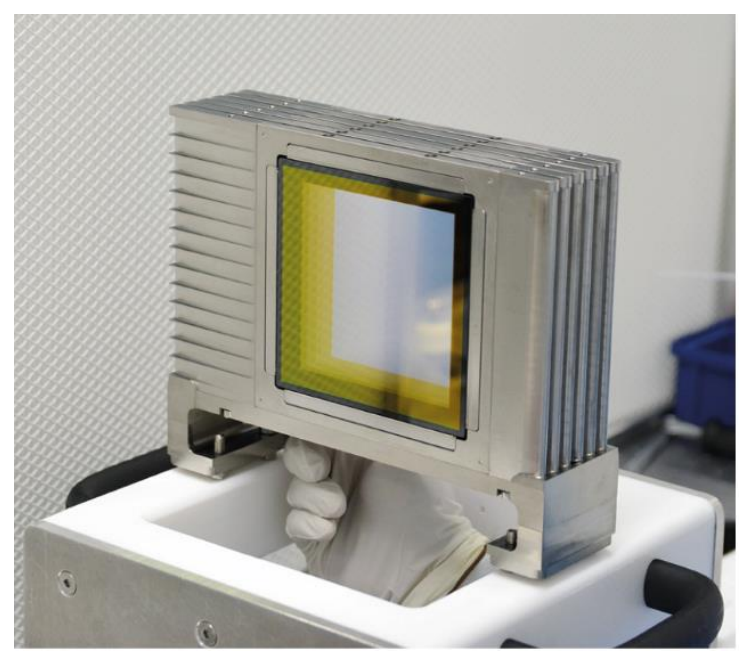

Figure 18. Transparent ceramic laser gain media of Yb:YAG with Cr:YAG cladding from main amplifier HZ2 of Bivoj system [David 2019] 


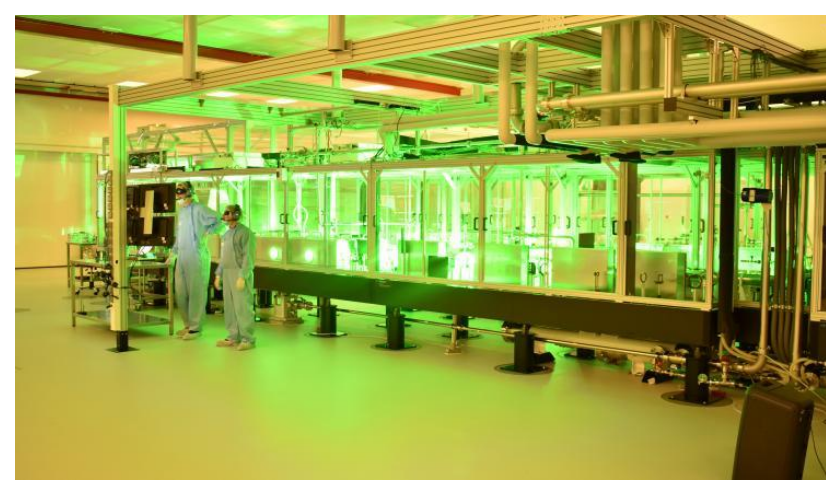

Figure 19. The L3-HAPLS advanced petawatt laser system located at the ELI Beamlines Research Center, Czech Republic [Livermore 2018]

Highly scalable Total-Reflection Active Mirror concept called GENBU (Generation of ENergetic Beam Ultimate, see Figure 20) devised by Kawanakas group in Japan promises above $1 \mathrm{~kW}$ output power once completed [Kawanaka 2008], [Furuse 2012]. First section of the amplifier was tested [Tokita 2017] and now $100 \mathrm{~J} 100 \mathrm{~Hz}$ system is under construction [Tokita 2019].

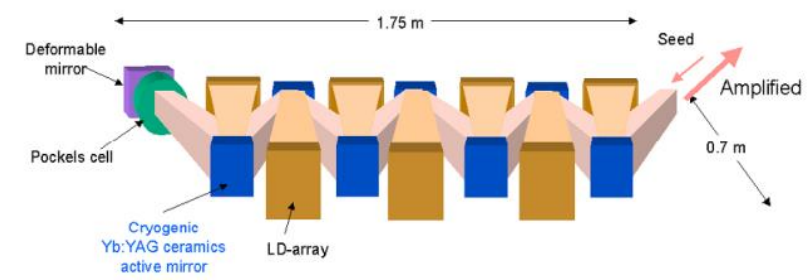

Figure 20. Main Amplifier design concept of GENBU laser based on Total-Reflection Active Mirrors (TRAM) [Kawanaka 2009]

\section{CONCLUSIONS}

A slow and steady evolution of electronics manufacture did not only spread cheap phones and computers among us, it brought a revolution into the laser world. Affordable laser diodes broaden the possibilities of manufacturing and science. The laser technology behind scenes is getting more and more complex and interesting. This article should provide a brief insight into a modern high average power diode pumped laser technology.

\section{ACKNOWLEDGMENTS}

This research was co-financed by the European Regional Development Fund and the state budget of the Czech Republic (project HiLASE CoE, CZ.02.1.01/0.0/0.0/15_006/0000674) and by the Ministry of Education, Youth and Sports of the Czech Republic (Programmes NPU I Project No. L01602, Large Research Infrastructure Project No. LM2015086).

\section{REFERENCES}

[Abineri 2019] Abineri, J. Direct Diode Lasers: IDTechEx Research Reviews How Technology Evolution is Opening New Markets. IDTechEx, 2019, Boston [online]. Jul 05, 2019 [Oct 5, 2019]. $<$ https://www.prnewswire.com/news-releases/direct-diodelasers-idtechex-research-reviews-how-technology-evolution-isopening-new-markets-300880312.html>

[Abineri 2019] Abineri, J. Laser Diodes: IDTechEx Research Reviews How Smartphones and Self-Driving Cars See the World. IDTechEx, 2019, Boston [online]. Jul 15, 2019 [Oct 5, 2019]. <https://www.prnewswire.com/news-releases/laser-diodesidtechex-research-reviews-how-smartphones-and-self-drivingcars-see-the-world-300884895.html>.

[Alferov 2000] Alferov, Z. I., Double Heterostructure Lasers: Early Days and Future Perspectives. IEEE J. Sel. Top. Quant. Electron. 2000, 6: 832 - 840

[Chyla 2018] Chyla M. Status and Development of High Average Power Lasers at HiLASE, CLEO 2018, San Jose, United States of America, May 14, 2018

[Danson 2015] Danson, C. Petawatt class lasers worldwide. High Power Laser Science and Engineering, 2015, 3, 3

[David 2019] David, S.P. et al. Transparentni keramika pozehnani pro spolecenstvi laserovych vedcu. Ceskoslovensky casopis pro fyziku, 2019, 4, 69, 258 - 263

[Dilas 2019] Dilas, C., Product Search. Coherent|Dilas, 2019, http://www.dilas.com. [Oct 5, 2019]. $<$ http://www.dilas.com/products/search/vertical-stacked>

[Furuse 2012] Furuse H. 1J, $100 \mathrm{~Hz}$ GENBU-Front End Laser System with Multi-TRAMs, HEC-DPSSL 2012, Tahoe City, United States of America, September 11, 2012

[Giesen 1994] Giesen, A. et al. Scalable Concept for DiodePumped High-Power Solid-State Lasers. Appl. Physics B, 1994 58, 365

[Hamamatsu 2018] Hamamatsu, P., News release. Hamamatsu Photonics, Hamamatsu City, 19 April, 2018, www.hamamatsu.com. [Oct 5, 2019]. $<$ https://www.hamamatsu.com/resources/pdf/news/2018_04_ 19_en.pdf\#page $=1 \& z o o m=220,-27,396>$

[II-VI 2019] II-VI Laser Enterprise, Edge Emitting Lasers. II-VI, 2019, www.ii-vi.com. [Oct 5, 2019].

$<$ https://www.ii-vi.com/edge-emittinglasers/?SingleProduct $=881>$

[Injeyan 2011] Injeyan, H. et al. High-Power Laser Handbook. McGraw-Hill Professional, 2011. ISBN 978-0-07-160901-2

[IPG 2019] IPG Photonics, Diode Laser Solutions. IPG Photonics, 2019, www.ipgphotonics.com. [Oct 5, 2019]. <https://www.ipgphotonics.com/en/products/lasers/diodelaser-systems\#[overview-8]>

[Kaminskii 1990] Kaminskii, K. Laser Crystals: Their Physics and Properties, 2nd ed. Springer, Berlin, 1990. ISBN 978-3-54052026-9

[Kawanaka 2008] Kawanaka J. et al. "GENBU"-Laser Development with Cryogenic Yb:YAG Ceramic for Fusion Energy Reactor Driver, 22 ${ }^{\text {nd }}$ IAEA Fusion Energy Conference, 2008. Geneva, Switzerland, October 13-18, 2008 
[Kawanaka 2009] Kawanaka J. Recent Status of "GENBU"-Laser, HEC-DPSSL 2009, Dresden, Germany, June 10, 2009

[Khazanov 1999] Khazanov, E. A. et al. Investigation of SelfInduced Depolarization of Laser Radiation in Terbium Gallium Garnet, IEEE J. Quantum Electron., 35. 1116, 1999

[Kurata 2019] Kurata, M. et al. Development of a $100 \mathrm{~J}$ Class Cryogenically Cooled Multi-disk Yb:YAG Ceramics Laser. Laser Congress 2019, OSA Technical Digest, 2019.

[Livermore 2018] Livermore, L. N. L. LLNL-developed petawatt laser system fully integrated, operational at ELI Beamlines. Lawrence Livermore National Laboratory, 2018, Livermore [online]. [Oct 5, 2019]. <https://www.IInl.gov/news/Ilnldeveloped-petawatt-laser-system-fully-integrated-operationaleli-beamlines>

[Livermore 2019] Livermore, L. N. L. What is NIF?. Lawrence Livermore National Laboratory, 2019, Livermore [online]. [Nov 15, 2019]. < https://lasers.IInl.gov/about/what-is-nif >

[Livermore1 2019] Livermore, L. N. L. Operations Team Keeps the Lasers Firing. Lawrence Livermore National Laboratory, 2019, Livermore [online]. [Oct 5, 2019]. <https://lasers.IInl.gov/10-years-of-dedication/facilityoperations>

[Livermore21 2019] Livermore, L. N. L. High-Average-Power Laser-Diode Arrays. Lawrence Livermore National Laboratory, 2019, Livermore [online]. [Oct 5, 2019]. $<$ https://lasers.IInl.gov/science/photon-science/highpoweredlasers/hapl>

[Livermore32 2019] Livermore, L. N. L. Directed Energy. Lawrence Livermore National Laboratory, 2019, Livermore [online]. [Oct 5, 2019]. <https://lasers.IInl.gov/science/photonscience/directed-energy>

[Machan 2002] Machan, J. P. et al. 5.4 kW Diode-Pumped, 2.4x Diffraction-Limited Nd:YAG Laser for Material Processing. Proc. Advanced Solid State Laser Conf., 2002, 549
[Mason 2017] Mason, P. et al. Kilowatt average power $100 \mathrm{~J}$-level diode pumped solid state laser. Optica, 2017, 4, 438

[Scheps 2002] Scheps, R. Introduction to Laser Diode-Pumped Solid State Lasers. Spie Publications, 2002. ISBN 0-8194-4274-7

[Stark 2011] Stark, M., IPG Laser GmbH. Polybright, Turin, 15 May 2011, www.ipgphotonics.com. [Oct 5, 2019]. <https://polybright.eu/file_153891.pdf>

[Sugioka 2014] Sugioka, K., Cheng, Y. Ultrafast lasers-reliable tools for advanced materials processing. Light: Science \& Amp, Applications, published online 11 April 2014, 3, e149

[Tian 2015] Tian, Y.M. et al. High-aluminum phosphate glasses for single-mode waveguide-typed red light source. J. Non-Cryst. Solids, 2015, 426, 25-31

[Tokita 2017] Tokita S. Development Status of GENBU Laser. HEC-DPSSL 2017, Noboribetsu, Japan, May 24, 2017

[Tokita 2019] Tokita S. Overview of 100J, 100Hz DPSSL. HEC-DPSSL 2019, Daejeon, Korea, January 16, 2019

[Trumpf 2019] Trumpf, TruDisk 12001. Trumpf, 2019, www.trumpf.com. [Oct 15, 2019] <https://www.trumpf.com/ cs_CZ/produkty/laser/diskovy-laser/trudisk/>

[Weck 2008] Weck, A. et al. Laser drilling of high aspect ratio holes in copper with femtosecond, picosecond and nanosecond pulses. Appl. Phys. A 90, 2008, 537-543

[Welch 2000] Welch, D. F. A Brief History of High-Power Semiconductor Lasers. IEEE J. Sel. Top. Quant. Electron., 2000, 6, 1470-1477

[Wikipedia 2009] Wikipedia, National Ignition Facility. Wikipedia, 2009, en.wikipedia.org. 4 September 2015 [Oct 5, 2019].

<https://en.wikipedia.org/wiki/National_Ignition_Facility >

[With 1984] With, G., Dijk, van H. J. A. Translucent $\mathrm{Y}_{3} \mathrm{Al}_{5} \mathrm{O}_{12}$ Ceramics. Material Research Bulletin 19, 1984, 1669

\section{CONTACTS:}

RNDr. Martin Hanuš Ph.D.

Instite of Physics, HiLASE Centre

Za Radnicí 828, Dolní Břežany, 252 41, Czech Republic

+420 314007 712, martin.hanus@hilase.cz,www.hilase.cz 